\title{
EFFECT OF TRADITIONAL SOLUBLE AND SLOW RELEASE N-FERTILIZERS ON WHEAT \& THEIR RESIDUAL EFFECT ON SORGHUM AND BARLEY IN SOME SOILS OF EGYPT
}

\author{
H. A. Madkour, T.A. Aboul-Defan and S.A.A. El-Raies \\ Soil, Water and Environ Res. Instit. Agric. Res. Cent (ARC) Giza- Egypt
}

Received: Aug. 27, 2017

Accepted: Oct. 1, 2017

\begin{abstract}
A pot experiment was conducted under greenhouse conditions using pots (perforated at the bottom), with $12 \mathrm{~kg}$ soil capacity of each. Pots were seeded with wheat (Triticum aestivum c.v. Sakha 8), to study the effects of traditional soluble-N and slow release- $N$ fertilizers. The soil of each pot was thoroughly mixed with $P$ at a rate of $12 \mathrm{mg} \mathrm{P/kg}$ soil. Soil $\mathrm{K}$ was in sufficient amount. The experimental pots were contained 288 pots, which arranged in a complete randomized block design with three replicate in four factors of three forms of soil , four $N$-fertilizers ( two traditional soluble- $N$ and the other two slow release- $N$ fertilizers), three rates of $\mathrm{N}$-fertilizers as well as two rates of moisture regimes of 70 and $100 \mathrm{WHC}$. At wheat maturity after 24 weeks-growth, plants in each pot were cut 2-cm above soil surface, carefully washed, dried and weighted. After wheat harvested and in the same pots, in order to study the Nfertilizes residual effect, two successive crops of Sorghum vulgar "c.v. Giza 15" and then barley "Hordium, vulgar c.v. Giza 121" were planted and harvested after 9 and 16 weeks, respectively. The obtained results may be summarized as follows:

- The traditional soluble forms of N-fertilizers produced higher dry matter (gm./pot) of wheat crop compared with the slow release forms of $\mathrm{N}$-fertilizers.

- Dry weights (gm/pot) of both sorghum and barley were more under fertilization with slow release forms of $\mathrm{N}$-fertilizers, than under fertilization with the traditional soluble forms, with approximately equal to two fold and threefold, respectively.

- Slow release forms resulted in less $N$-uptake by wheat than the traditional soluble forms. While the slow release forms of $\mathrm{N}$-fertilizers affected positively on $\mathrm{N}$-uptake by both of sorghum and barley, with increases approximately equal to twice threefold more than the traditional soluble ones.

- Residues of slow release $N$ - fertilizers have appropriate supply of sorghum and barley, at the two successive with amounts of $(N)$, because their ability to continuous supply $(N)$ for long periods of time.
\end{abstract}

Key word: Traditional soluble N-fertilizers - Slow releases $N$ - fertilizers - Water holding capacity - Field crops - Soils.

\section{INTRODUCTION}

Wheat is one of the most ancient crops of the world. It was cultivated as long as 6500 years ago on the territory of present-day Iraq, 600 years B.C. in Egypt, and 25003000 years B.C. in India and China. Wheat is the leading food crop in world farming. It occupies over $30 \%$ (238 million hectares) of the crop area under all grain cultures (760 million hectares). Wheat is the main food crop for the nations living in the temperate zone, (Ustimenko-Bakumovsky 1983).
Sorghum has a number of features which make it a drought-resistant crop. The crop does well on most soils but better so in light to medium textured soil, (Doorenbos et al. 1986). The main crop areas under sorghum are concentrated in the countries of a hot dry climate, (Ustimenko-Bakumovsky 1983).

Barley crop areas are mainly situated in the regions of the temperate zone, but it is also raised on large territories in the subtropics and even in the mountain regions 


\section{H. A. Madkour, et al.,}

of the tropical belt, (Ustimenko-Bakumovsky 1983).

Nitrogen-release from sulphur coated urea (SCU) particles is directly affected by the thickness and quality of the coating. The dissolution of urea into the soil solution follows microbial and hydrolytic degradation of the protective sulphur coating and the presence of micro pores and imperfection, i.e. cracks and complete sulphur coverage. Typically, there are three forms of coatings: damaged coating with cracks, damaged coating with cracks sealed with wax, and perfect coating. SCU-fertilizers may contain more than one third of granules with damaged coating and about one third of perfectly coated granules. Therefore, one third or even more of the urea may be released immediately after contact with water (so-called 'burst'), and one third may be released long after it is required by the plant (so-called 'lock-off' effect) (Shaviv, 2001 and 2005). Urea has 46\%N and after coating with sulphur, (SCU) still contain about 30-40\% N, (Trenkel, 2010).

The release pattern of nitrogen from urea-formaldehyde (UF) $(38 \% \mathrm{~N})$ fertilizers is multi-step process (dissolution and decomposition). In general, some proportion of the $\mathrm{N}$ is released slowly (Fraction $\mathrm{I}$ ); this is followed by a more gradual release over a period of several (3-4) months (Fraction II) depending on the product form. However, the release pattern is also influenced by the soil temperature and moisture, as well as by soil organisms and their activity. UF fertilizers show a significant slow release of nitrogen with a good compatibility with most crops. Because of its low solubility it will not scorch vegetation of impair germination. Because it is more effective at higher temperatures, it is widely used in warmer climates, (Trenkel 2010).

Nitrogen availability depends on amount and form of applied-N, soil available- $\mathrm{N}$, soil type \& condition, crop rotation and cultivation history of the field, as well as on temperature and precipitation during the growing season (Aucklah et al., 1991, Poutala 1998, Przulj and Momcilovic 2001, Muurnen 2007).

Management strategies to reduce soil $\mathrm{N}$ loss include improved timing of $\mathrm{N}$ - fertilizer applications, better use of soil and plants testing procedures to determine $\mathrm{N}$ availability, application of nitrification or urease inhibitors, and use of $\mathrm{N}$-fertilizer sources that are suitable for local environmental conditions (Dinnes et al., 2002). The optimum growth of plants there must be a balance between the rate of photosynthetic production and the rate of $\mathrm{N}$ assimilation. Also under conditions of high photosynthetic activity, N-nutrition must be high and vice versa (Slack and Hatch, 1967).

The release of $\mathrm{N}$ by the slow-release fertilizer tested in this trial was too slow for the cool growing conditions. Slow release of $\mathrm{N}$-fertilizer in coated treatments had an apparent effect on plant $\mathrm{N}$ status throughout the growing cycle. Lower $\mathrm{N}$ availability reduced plant $\mathrm{N}$-content at heading stage. Lower grain and straw $\mathrm{N}$-content and lower plant $\mathrm{N}$-uptake indicate lower $\mathrm{N}$-availability also at grain filling period, (Rajala and Peltonen-Sainio (2013).

This research aims to study the effect of slow release $\mathrm{N}$-fertilizers "i.e. sulphur-coated urea "SCU" and urea formaldehyde "UF" as well as traditional soluble forms of $\mathrm{N}$ fertilizers of calcium nitrate "CaN" and ammonium sulphate "NH" on dry weighs of wheat, sorghum and barley cultivated in some soils of Egypt under two moisture regimes of $70 \% \mathrm{WHC}$ and $100 \%$ WHC. Also, $\mathrm{N}$ uptake by the cultivated plants was studied.

\section{MATERIALS AND METHODS}

A pot experiment was conducted under green house conditions using pots (perforated at the bottom), with $12 \mathrm{~kg}$ capacity of each. The soil of each pot was supplied, through mixed thoroughly, with $\mathrm{P}$ at a rate of $12 \mathrm{mg} \mathrm{P/kg}$ soil. Soil-K was in 
sufficient amount. The experimental pots were contained 288 pots representing, i.e. "3 soils" x "4 N-fertilizer forms" $x$ "4 N-rates" $x$ "2 moisture of WHC" $x$ "3 replicates" which arranged randomized in a complete block design with three replicate in four factors of:

(1) Soils: surface $(0-20 \mathrm{~cm})$ soil samples were taken separately from three different locations of Egypt. These locations were Experimental Farm of Soil, Water and Environment Research Institutes (ARC) Giza (Giza Governorate), and Experimental Farm of El-Nobaria and El-Tahreer station ARC, of Nobaria and El-Tahreer (Behaira Governorate) respresinting alluvial, calcareous and sandy soils respectively. The collected soil samples were air-dried, ground, sieved through a $2 \mathrm{~mm}$ sieve. Their textures were clay loam, sandy clay loam and sandy loam, respectively.

(2) N-Fertilizers: They were two traditional soluble $\mathrm{N}$-fertilizers of calcium nitrate $(15.5 \% \quad \mathrm{~N}, " \mathrm{CaN} ")$ and ammonium sulphate $(21 \% \mathrm{~N}, " \mathrm{NH})$. As well as two slow release $\mathrm{N}$-fertilizers of sulphurcoated urea $(28 \% \mathrm{~N}$, "SCU"), and urea formaldehyde (31\%N, "UF").

(3) Rates of N-fertilizers: They were 0.0, 2.4, 3.6 and 5.4 (gm N/pot).

(4) Moisture regimes: Represented with $70 \%$ and $100 \%$ of Water Holding Capacity (WHC).

Pot were seeded with wheat (Triticum aestivum c.v. Sakha 8), at the winter season of 2015/2016 , at a rate of 15 seeds/pot and thinned to 10 seedlings/pot after emergence. At maturity (24 weeks-growth), plants in each pot were cut 2-cm above soil surface, carefully washed, dried and weighed, ground digested and analyzed for (N) as mentioned by Black et al., (1965).

To study the response of successive crops to the residual effects of $\mathrm{N}$-fertilizers, 2 successive crops were planted. They were sorghum "Sorghum vulgare c.v. Giza 15" which planted at the following summer season of 2016 and harvested after 9 weeks, then barley "Hordium, vulgare c.v. Giza 121" which planted at the next winter season of 2016/2017 and harvested after 16 weeks. Plants in each pot were cut as an all plant at 2-cm above soil surface, carefully washed, dried and weighed, ground digested and analyzed for $(\mathrm{N})$ as described by Black et al., (1965).

Soil samples were analyzed for some physical and chemical properties according to the methods described by (Piper, 1950) and (Black et al, 1965). The obtained data are recorded in Table (1). Data were statistically analyzed as Sndecor and Coechran (1971) using computer M. Stat. program.

\section{RESULTS AND DISCUSSION}

Sulphur-coated urea (SCU) is broken down by microorganisms, chemical and mechanical action. The nitrogen in (SCU) is released more readily in warm temperatures and dry soil. SCU appears to be more effective when applied to the soil surface, rather than mixed into the soil.

The conversion of urea formaldehyde (UF) reaction products to plant-available $\mathrm{N}$ is a multi-step process, involving first dissolution, and microbial decomposition. Once in the soil solution, UF reaction products are converted to plant-available $\mathrm{N}$ through either microbial decomposition or hydrolysis. Microbial decomposition is the primary mechanism of $\mathrm{N}$ release. Environmental factors such as soil temperature, moisture, $\mathrm{pH}$ and aeration affect microbial activity and, therefore, the rate of $\mathrm{N}$ release.

\section{Effects $\mathrm{N}$-fertilizers on wheat growth \\ Wheat dry matter yield (gm. /pot)}

Collected graphs in Fig. (1), declared the individual mean effects of $\mathrm{N}$-fertilizers form, $\mathrm{N}$-fertilizers rates, soil type and soil moisture regimes on dry weights (gm. /pot) of wheat. 
H. A. Madkour, et al.,

Table (1) : Analysis of the experimental soils.

\begin{tabular}{|l|c|c|c|}
\hline Characteristics & Giza & El-Noubria & El -Tahreer \\
\hline \multicolumn{1}{|c|}{ And units } & Alluvial & Calcareous & Sandy \\
\hline EC (dS/m) (past extract) & 1.74 & 1.47 & 0.98 \\
\hline $\mathrm{pH}(1.2 .5$ soil:water) & 8.0 & 8.2 & 7.8 \\
\hline O.M. \% & 1.93 & 1.43 & 1.18 \\
\hline CaCO $\%$ & 2.94 & 31.7 & 3.15 \\
\hline Total N \% & 0.1 & 0.04 & 0.03 \\
\hline Available P (mg/kg) & 23.8 & 6.2 & 5.4 \\
\hline Available K (mg/kg) & 390.0 & 151.0 & 112.0 \\
\hline Clay \% & 40.1 & 14.9 & 8.2 \\
\hline Silt \% & 28.5 & 22.5 & 16.6 \\
\hline Sand \% & 31.4 & 62.6 & 75.2 \\
\hline Soil Texture & Clay Loam & Sandy Clay Loam & Sandy Loam \\
\hline
\end{tabular}

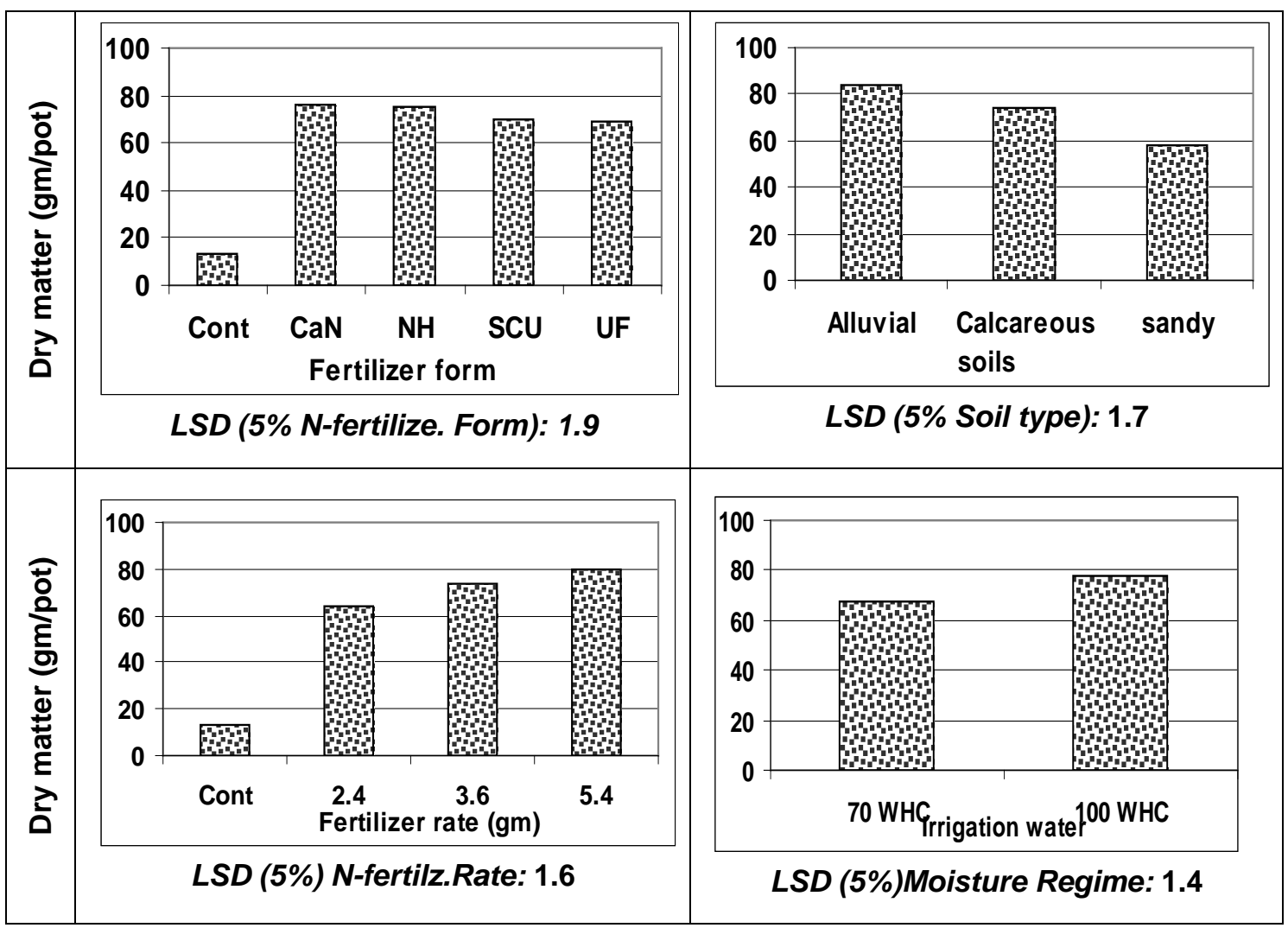

Fig (1): Mean effects of the individual $\mathrm{N}$-fertilizers form, $\mathrm{N}$-fertilizer rates, soil types and soil moisture regimes on wheat dry weights (gm. /pot) . 
As for the effects of $\mathrm{N}$-fertilizers forms \& rates (gm N/pot), in general, graphs showed that all $\mathrm{N}$-fertilizer forms and rates increased dry weights of wheat plants ( $\mathrm{gm} / \mathrm{pot})$ in compare with the control treatment $(0 \mathrm{~N}$ fertilizer). On the other hand, traditional soluble $\mathrm{N}$-fertilizers of $\mathrm{CaN} \& \mathrm{NH}$ were more effective in increasing dry matter than slow release $\mathrm{N}$-fertilizers of SUC \& UF. Whereas, the mean values of dry matter were 75.9 , $75.1,69.9$ and $69.4 \mathrm{gm} /$ pot when fertilized by $\mathrm{CN}, \mathrm{NH}, \mathrm{SCU}$ and UF, respectively. While, as for $\mathrm{N}$-fertilizer rate, the average values of dry matter for rates $2.45,3.6$ and $5.6 \mathrm{gm} /$ pot were $64.2,73.5$ and $80.2 \mathrm{gm} /$ pot for the mentioned rates, respectively.

Also the average vales of dry matter for soils of alluvial, calcareous and sandy were 84.0, 74.0, $57.8 \mathrm{gm} /$ pot, respectively. From another side, dry matter of wheat plants (mg/pot) recorded the highest values under moisture regimes of $100 \%$ than $70 \% \mathrm{WHC}$.
With respect to the dual interaction mean effects of $\mathrm{N}$ - fertilizers forms with any of the other experimental factors of $\mathrm{N}$-fertilizers rates, soil type and moisture regimes, Fig (2) showed that the rate of 5.4 (gm.N/pot) of $\mathrm{CaN}$ recorded the highest wheat dry matter (gm. /pot) compared to control and the other rates and forms of $\mathrm{NH}, \mathrm{SCU}$ and UF.

Fertilization with CaN in alluvial soil yielded higher wheat dry matter (gm. /pot) than the yielded of other $\mathrm{N}$-fertilizers forms in the other soils. Also the application of traditional soluble $\mathrm{N}$-fertilizers forms under moisture regime of $100 \% \mathrm{WHC}$, of $\mathrm{CaN}$ or $\mathrm{NH}$ achieved higher wheat dry matter (gm. /pot) followed with slow release $\mathrm{N}$-fertilizers of SUC or UF \& moisture regime of $100 \%$ WHC. While, CaN or NH \& $70 \%$ WHC then SUC or UF \& moisture regime of $70 \%$ WHC occupied the third and the fourth ranks, respectively.

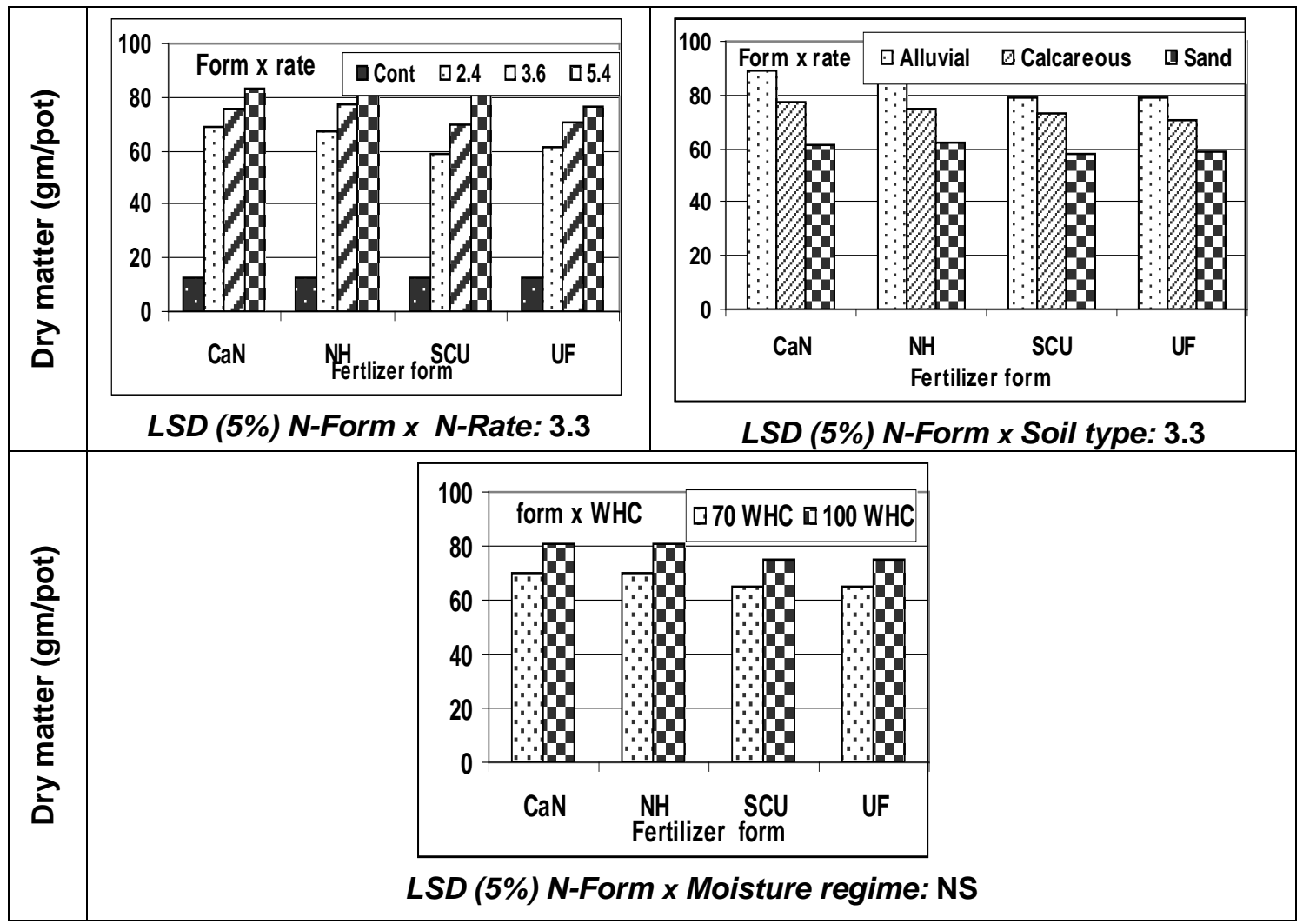

Fig (2): Mean effects of the dual interactions of (N-fertilizers forms $x$ N-fertilizers rates), ( $\mathrm{N}$-fertilizers forms $x$ soil type) and ( $\mathrm{N}$-fertilizers forms $x$ moisture regimes) on wheat dry weight (gm. /pot). 
Fig. (3) showed dry matter weight of wheat plant (gm/pot) affected with the triple interactions of $\mathrm{N}$-fertilizers forms, $\mathrm{N}$ fertilizers rates, and moisture regimes. While Fig. (4) showed the mean effects of the triple interactions of $\mathrm{N}$-fertilizers forms, $\mathrm{N}$ fertilizers rates, and soil types on dry matter weight of wheat plant (gm/pot). The two figures showed that, the highest average of dry weight (gm/pot) resulted under fertilization with the tradition $\mathrm{N}$-fertilizers forms with high $\mathrm{N}$-rate on alluvial soils under irrigation of $100 \%$ moisture regime.

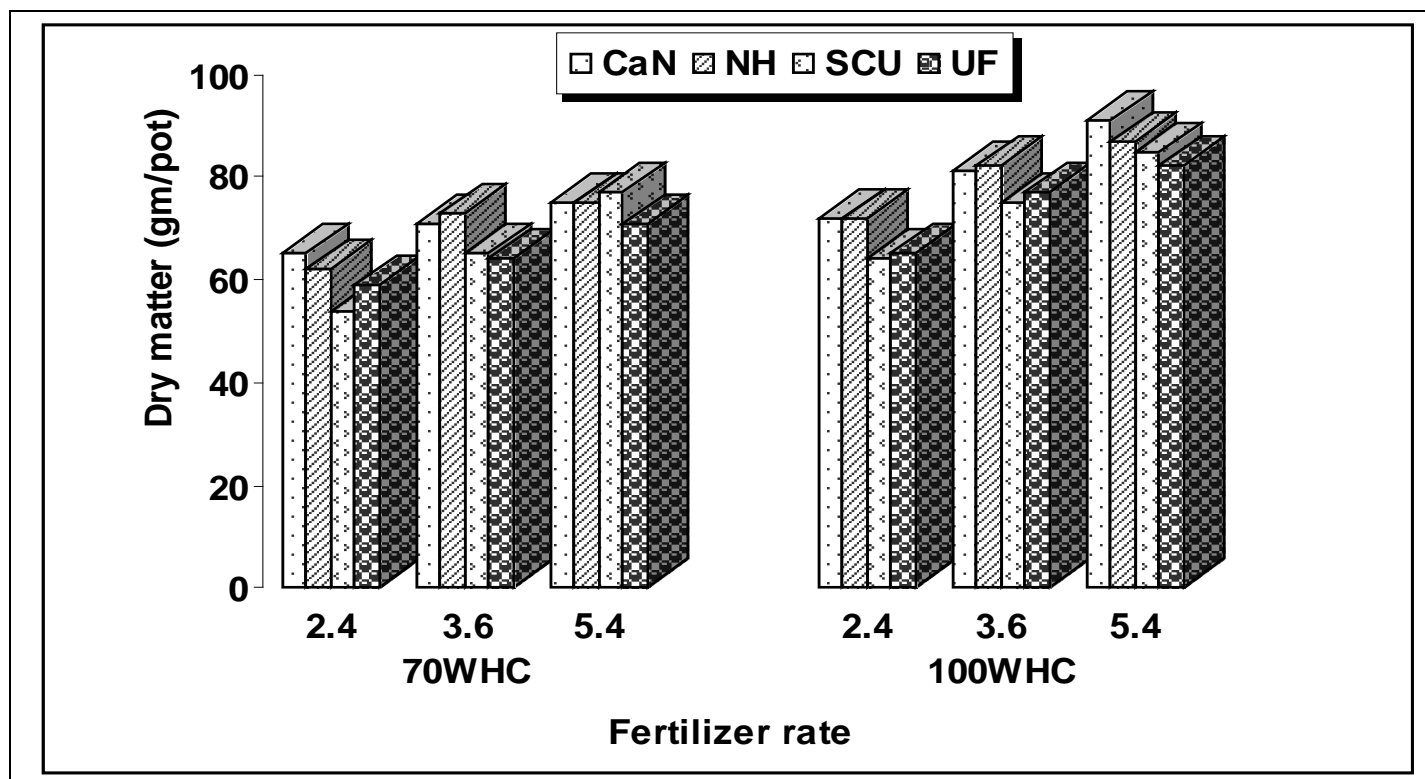

LSD (5\%) N-form $\times$ N-rate $\times$ moisture regime : N.S

Fig (3): Mean effect of the triple interaction of ( $\mathrm{N}$-fertilizer forms $x \mathrm{~N}$-fertilizer rate $\mathrm{x}$ moisture regimes) on wheat dry weight (gm/pot).

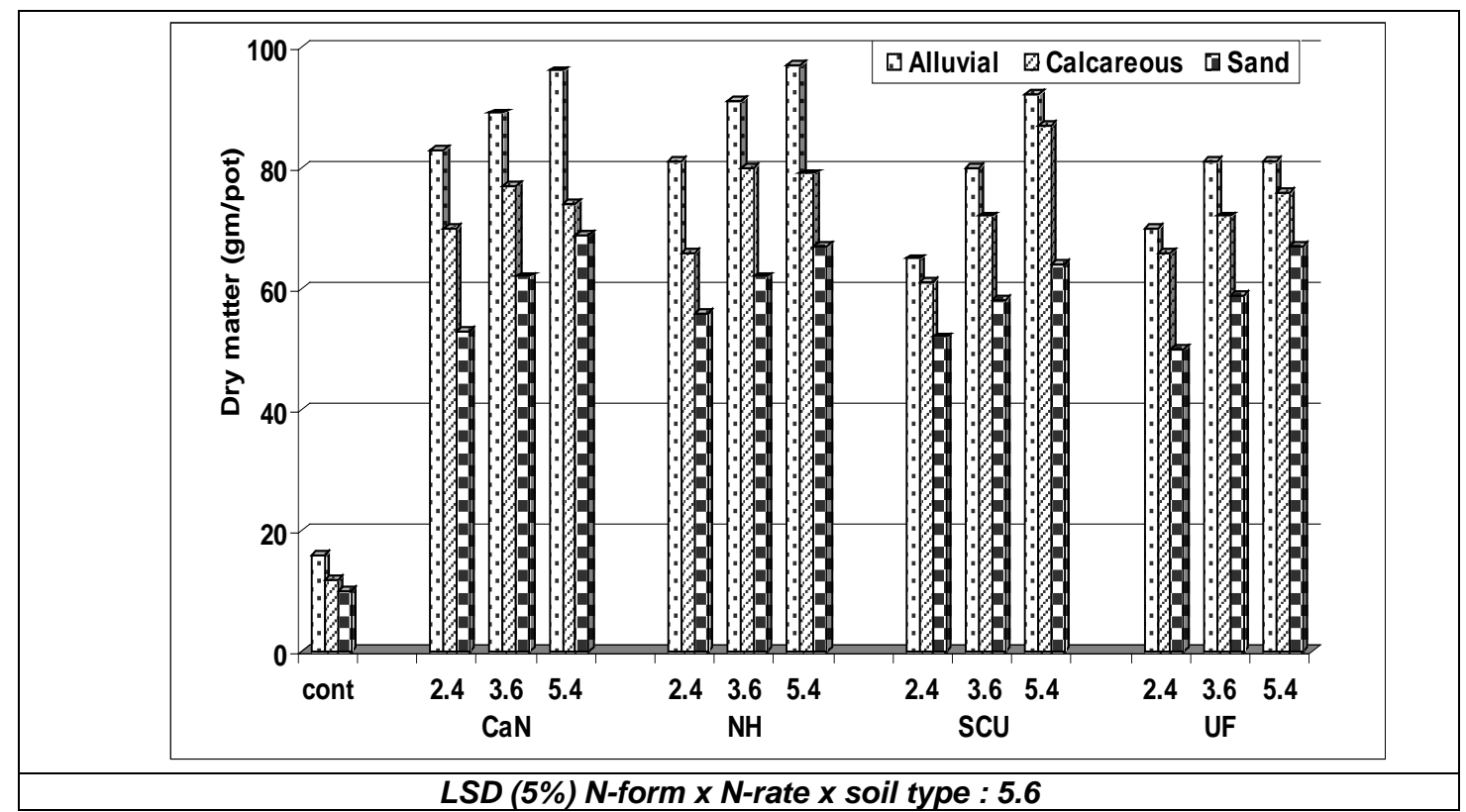

Fig (4): Mean effect of the triple interaction of ( $\mathrm{N}$-fertilizer forms $\times \mathrm{N}$-fertilizer rates $\mathrm{x}$ soil type ) on wheat dry weight (gmlpot). 


\section{Wheat $\mathrm{N}$-uptake (mg/pot)}

Data in Fig. (5) represented the individual mean effects of $\mathrm{N}$-fertilizers form, $\mathrm{N}$ fertilizers rates, soil type and soil moisture regimes on $\mathrm{N}$-uptake (mg. /pot) by wheat. Whereas, N-fertilizer form as CaN, Nfertilizers rate at $5.4(\mathrm{gm} / \mathrm{pot})$, alluvial soil and irrigation regime at $100 \% \mathrm{WHC}$ achieved the superiority $\mathrm{N}$-uptake than the other corresponding treatments.

While, the mean values of $\mathrm{N}$ - uptake were 983, 910, 776, and 786 (mg/pot) resulted from the treatments of the $\mathrm{N}$ fertilizer forms of $\mathrm{CaN}, \mathrm{NH}, \mathrm{SCU}$, and UF, respectively. As for the individual mean effects of $\mathrm{N}$-fertilizers rates $0.0,2.4,3.6$ and $5.4(\mathrm{gm} / \mathrm{pot})$, the mean values of $\mathrm{N}$-uptake were 112, 762, 871, and 951 (mg/pot), respectively. Also, the average values of $\mathrm{N}$ - uptake (mg/pot) by wheat, as affected by soil types, were 1000, 876 and $709 \mathrm{mg} /$ pot for alluvial, calcareous and sand soils, respectively. Whereas, the average values of $\mathrm{N}$ uptake (mg/pot) by wheat under the two irrigation regime were 793 and $930 \mathrm{mg} / \mathrm{pot}$ for 70 and $100 \mathrm{WHC}$, respectively.

The dual interaction mean effects of $\mathrm{N}$ fertilizers forms with any of the other experimental factors of $\mathrm{N}$-fertilizers rates, soil type and moisture regimes on $\mathrm{N}$-uptake (mg/pot) by wheat plants was shown in Fig. (6). It's clear showed that, dual interactions of fertilization wheat plants with $\mathrm{CaN}$ under $\mathrm{N}$-fertilizer rate at 5.4 (gm.N/pot) or under grown on alluvial soil or under moisture regime at $100 \%$ WHC produced higher $\mathrm{N}$ uptake by wheat plants $(\mathrm{mg} / \mathrm{pot})$ than the other dual interactions.

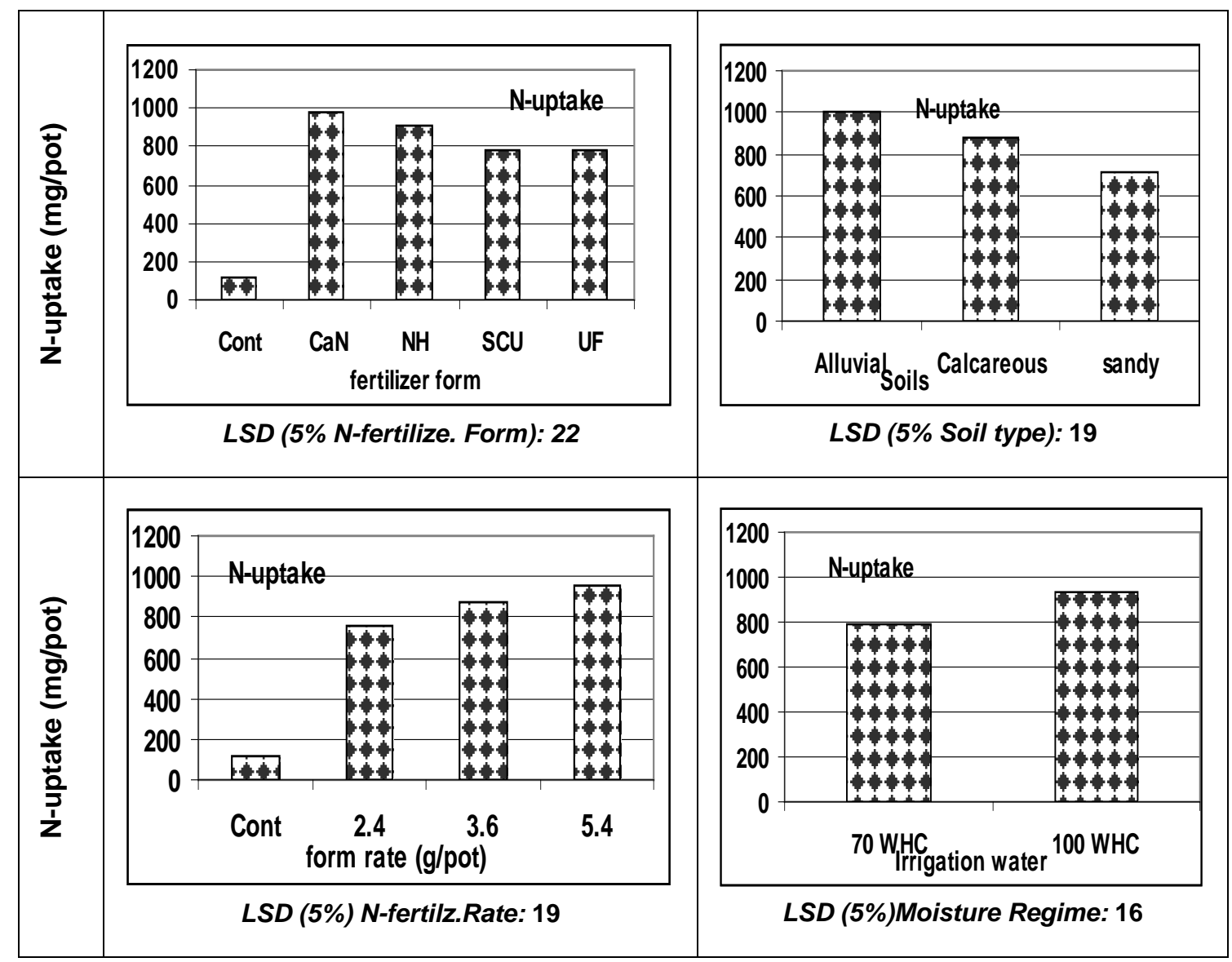

Fig (5): Mean effects of the individual $\mathrm{N}$-fertilizers form, $\mathrm{N}$-fertilizer rates, soil types and soil moisture regimes on Wheat $\mathrm{N}$-uptake (mg/pot). 


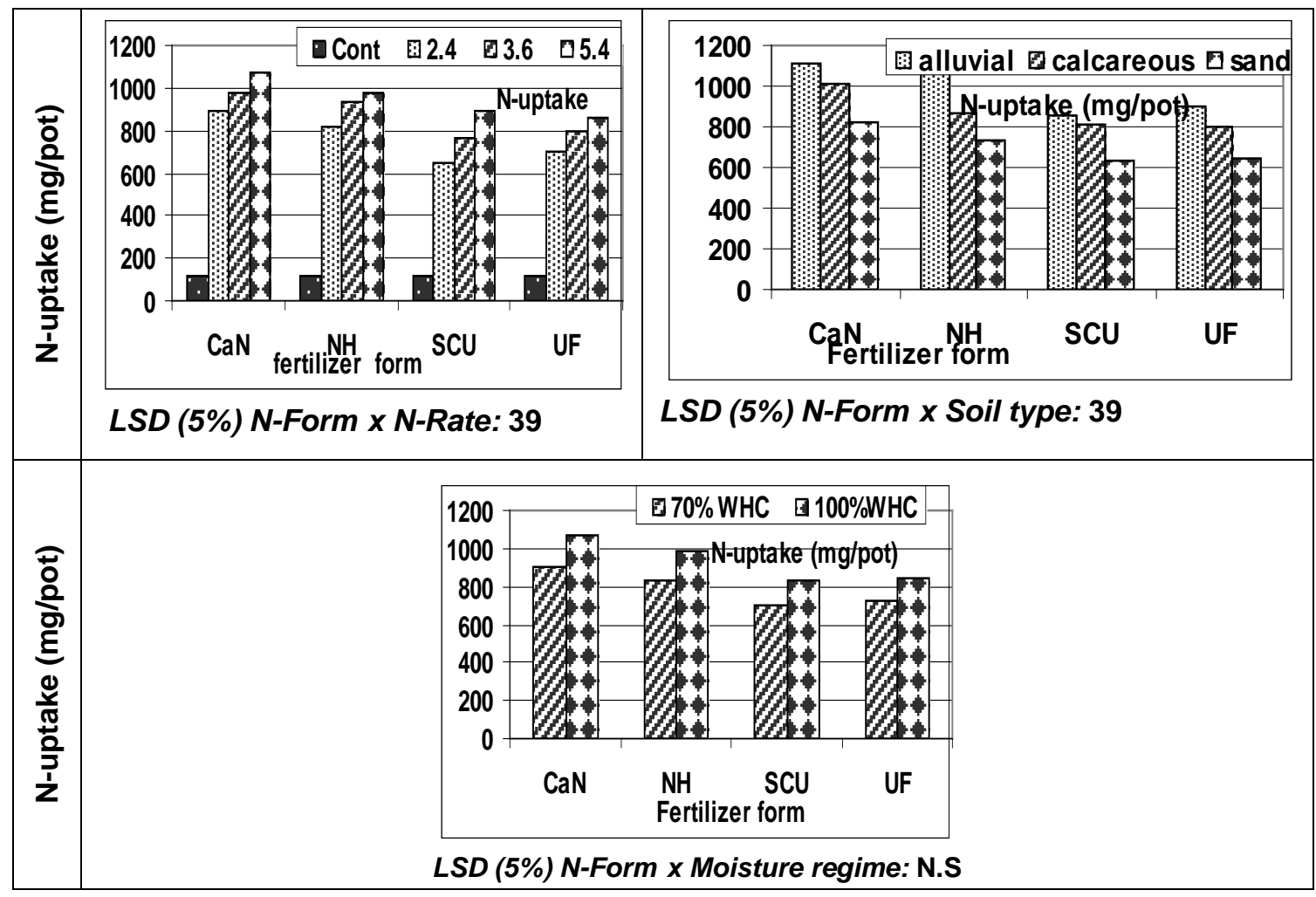

Fig (6): Mean effects of the dual interactions of ( $\mathrm{N}$-fertilizers forms $x \mathrm{~N}$-fertilizers rates), ( $\mathrm{N}$-fertilizers forms $x$ soil type) and ( $\mathrm{N}$-fertilizers forms $x$ moisture regimes) on $\mathrm{N}$ uptake (mg. /pot).

Fig. (7) show the effects of the triple interactions of the studied treatments $(\mathrm{N}$ fertilizer forms $x \mathrm{~N}$-fertilizer rates $x$ moisture regimes) on $\mathrm{N}$ uptake $(\mathrm{mg} / \mathrm{pot})$ by wheat plants. This figure showed increase of $\mathrm{N}$ uptake was found in the treatment of 5.4 (gm N/pot) as CaN with moisture regime of $100 \%$ WHC but with no significant trend with other similar interactions. On the other hand, Fig (8) showed the triple interaction of $\mathrm{N}$ fertilizer forms $x \mathrm{~N}$-fertilizer rates $x$ soil type on N-uptake (mg/pot) by wheat significant. Where these effects were as shown with trend supported the discussed trends.

The aforementioned data indicated that, dry matter (gm/pot) \& N-uptake (mg./pot) of wheat (which grown at the beginning of the experimental first winter season of 2015) under fertilization with quick-traditional soluble $\mathrm{N}$-fertilizers of $\mathrm{CaN} \& \mathrm{NH}$ were more than those fertilized with slow release $\mathrm{N}$ fertilizers of SUC \& UF can be considered an expected and a logical trend. This is due to the fact that, the quick-traditional soluble $\mathrm{N}$-fertilizers have insurance adequate needed of $\mathrm{N}$ for the growing plants of wheat during the vegetative growth stage faster than the $\mathrm{N}$-slow fertilizers. These $\mathrm{N}$-slow fertilizers have a continuous supply of crops with their needs of $\mathrm{N}$ for long periods of time. This supply may be continues for many subsequent seasons, then for other successive crops as a residual effect. A lot of studies were conducted in this field, such as the studies of Karrou, et al (2003), Silva et al (2007) and Ostrom (2011). On the other hand increasing dry matter (gm/pot) \& $\mathrm{N}$-uptake (mg/pot) of wheat with increasing $\mathrm{N}$-fertilization rate, regardless $\mathrm{N}$-fertilization form or soil type, were coinciding with the researches of Steve et al., (2012), Ladha et al., (2005), Halvorson et al. ,2005) and Irene et al. , (2015). 


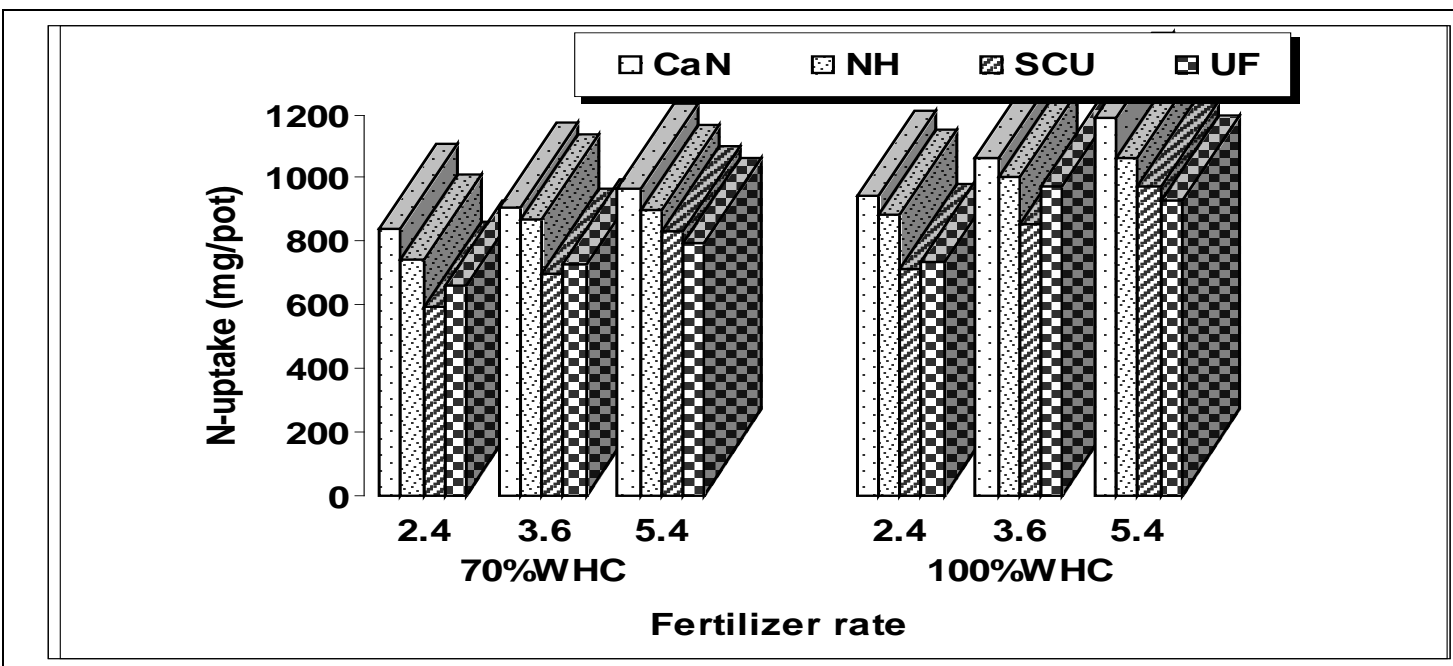

LSD (5\%) N-Form $\times$ N-Rate $x$ irrigation regime: N.S

Fig (7): Mean effects of the triple interactions of ( $\mathrm{N}$-fertilizer forms $x \mathrm{~N}$-fertilizer rates $x$ moisture regimes) on $\mathrm{N}$ uptake (mg./pot) by Wheat.

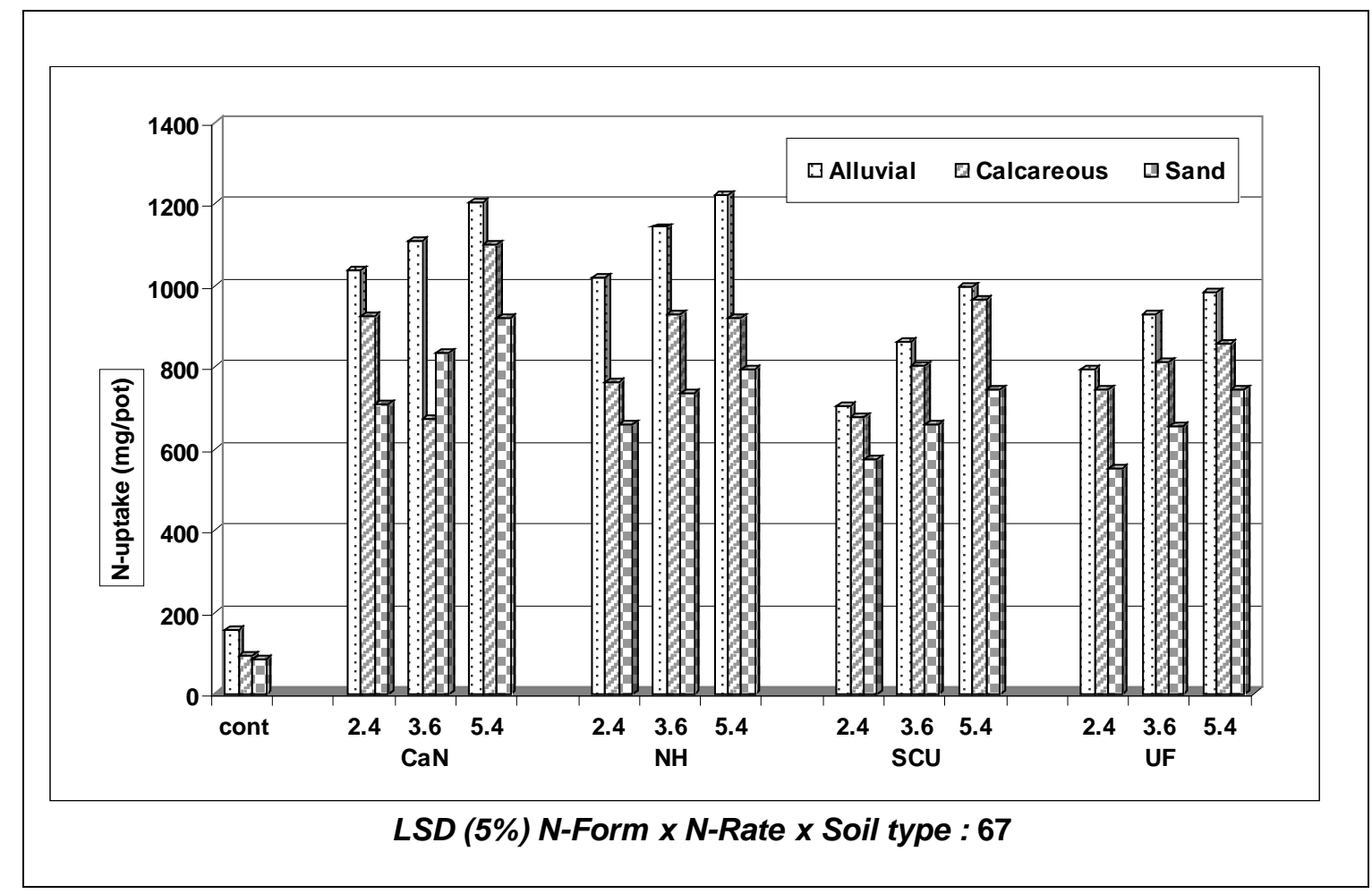

Fig (8): Mean effects of the triple interaction of ( $\mathrm{N}$-fertilizer forms $x \mathrm{~N}$-fertilizer rates $x$ soil type) on $\mathrm{N}$ uptake (mg./pot) by wheat . 
Furthermore, the superiority of increasing dry weight (gm/pot) \& N-uptake (mg/pot) of wheat was recorded in pots of alluvial soil follow with in pots of calcareous soil and the latest increasing was noticed in pots of sandy soils. While moisture regime of $100 \%$ WHC achieved higher dry weight (gm/pot) \& $\mathrm{N}$-uptake (mg/pot) of wheat was more than those under moisture regime of $70 \% \mathrm{WHC}$. These trends can be interpreted as Allan (2004) who stated that, the most important way in which soil texture affects plant growth is water and with it the nutrient supply. The available water holding capacity of soil is related to soil texture. Clayey soils show high water holding capacity, high plasticity, and stickiness and swelling, whereas sandy soils are conspicuous by the absence of these properties. Also Khafagi et al. (1987) reported that, nitrate ions movement in some Egyptian soil is strongly positively affected by moisture content of soil with a linear relationship.

\section{Residual effects of $\mathrm{N}$ - fertilizers on successive crops}

The second phase of the current search included the study of residual effects of the used $\mathrm{N}$ - fertilizers, with previous crop, on the successive crops. As mentioned previously, after wheat harvested and in the pots without any new additions of $\mathrm{N}$-fertilizers, "Sorghum" was planted at the following summer season for 9 weeks, then "Barley" was planted at the next winter season for 16 weeks.

With respect to the effects of $\mathrm{N}$-fertilizersrates, moisture regimes and soil types either as individual or as interaction on dry weight (gm/pot) and N-uptake (mg/pot) of sorghum and barley, they showed similar trends to the corresponding data of wheat, with a predominant tendency for significant differences between the experimental treatments as shown in Table (2).

Nevertheless, the residual effects $\mathrm{N}$ fertilizer forms on dry weight (gm./pot) and $\mathrm{N}$-uptake (mg./pot) of the successive crops i.e. sorghum and barley showed a contrary trends to their effects on the previous crop (wheat), as will be discussed later.

Table (2): LSD at $5 \%$ of residual effects of the used $\mathrm{N}$-fertilizers, with the previous crop , on the successive crops of sorghum and Barley.

\begin{tabular}{|c|c|c|c|c|}
\hline \multirow{3}{*}{$\begin{array}{l}\text { Different effects of the } \\
\text { experimental factors }\end{array}$} & \multicolumn{4}{|c|}{ LSD (5\%) values } \\
\hline & \multicolumn{2}{|c|}{ Sorghum } & \multicolumn{2}{|c|}{ Barley } \\
\hline & $\begin{array}{c}\text { Dry matter } \\
(\mathrm{gm} / \mathrm{pot})\end{array}$ & $\begin{array}{l}\text { N-Uptake } \\
\text { (mg/pot) }\end{array}$ & $\begin{array}{c}\text { Dry matter } \\
(\mathrm{gm} / \mathrm{pot})\end{array}$ & $\begin{array}{l}\text { N-Uptake } \\
\text { (mg/pot) }\end{array}$ \\
\hline $\mathrm{N}$-Fertilizer Form $(F)$ & 1.5 & 15 & 0.70 & 8.0 \\
\hline N-Form Rate $(R)$ & 1.0 & 13 & 0.60 & 7.0 \\
\hline Soils Types (S) & 1.0 & 13 & 0.60 & 7.0 \\
\hline Moisture Regime (M) & 0.8 & 11 & 0.47 & 6.0 \\
\hline$F \times R$ & 2.1 & 27 & 1.20 & 14.0 \\
\hline$F \times S$ & Ns & 27 & 1.20 & 14.0 \\
\hline$F \times M$ & 1.7 & 21 & 1.00 & 11.0 \\
\hline$F \times M \times R$ & Ns & Ns & Ns & Ns \\
\hline$F \times S \times R$ & Ns & 46 & 2.01 & 23.0 \\
\hline
\end{tabular}


Sorghum Dry matter (gm/pot) \& Nuptake (mg/pot).

Slow release $\mathrm{N}$-fertilizers forms SUC \& UF gave dry matter (gm./pot) and N-uptake (mg./pot) greater than the two forms of traditional soluble $\mathrm{N}$-fertilizers of $\mathrm{CaN} \& \mathrm{NH}$ (Fig. 9). The two slow-release forms gave dry matter (gm/pot) and N-uptake (mg/pot) twice greater than those of the traditional soluble $\mathrm{N}$-fertilizers forms. But, there was no significant difference between any of the two slow-release $\mathrm{N}$-fertilizer forms or between the two forms of traditional soluble $\mathrm{N}$ fertilizers.

\section{Barley Dry matter (gm/pot) \& N- uptake (mg/pot).}

Slow release $\mathrm{N}$-fertilizers forms of SUC \& UF gave dry matter (gm. /pot) and N-uptake (mg. /pot) greater than the two forms of traditional soluble $\mathrm{N}$-fertilizers $\mathrm{CaN} \& \mathrm{NH}$ (Fig. 10).

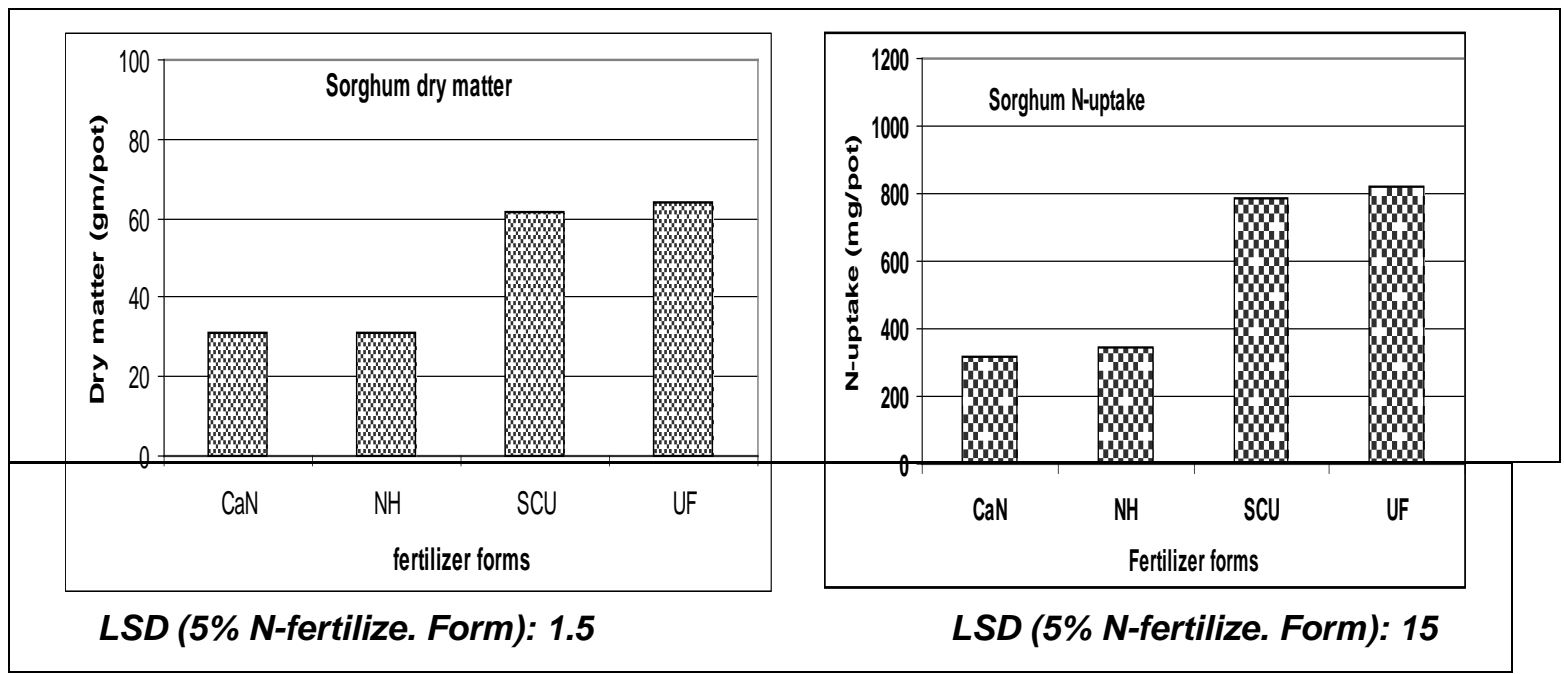

Fig (9): Mean residual effects of the individual N-fertilizers form on weights (gm. /pot) of Sorghum.

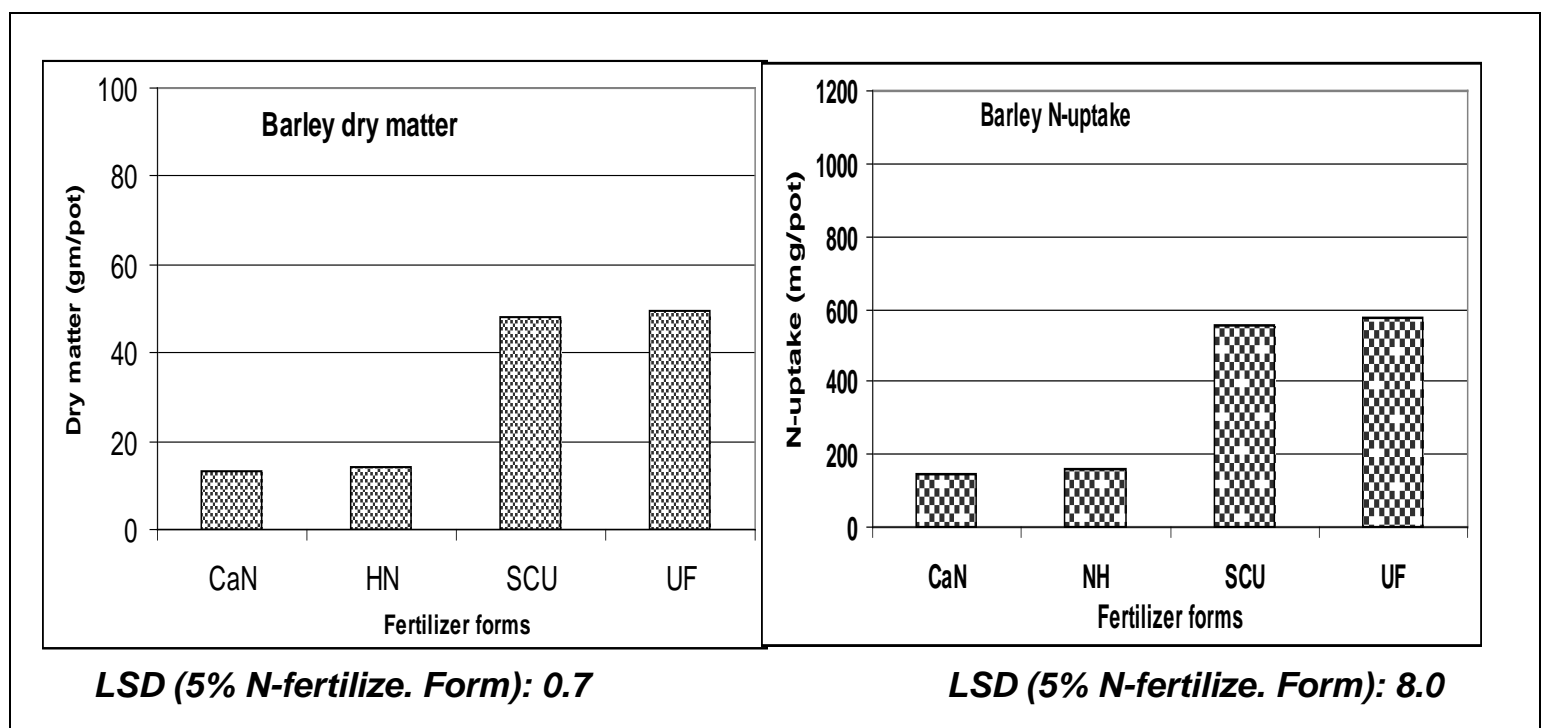

Fig (10): Mean residual effects of the individual N-fertilizers form on weights (gm. /pot) of Barley. 
The two slow-release forms gave dry matter (gm. /pot) and N-uptake (mg. /pot) threefold more than those of the traditional soluble $\mathrm{N}$-fertilizers forms. There was no significant difference between any of the two slow-release $\mathrm{N}$-fertilizer forms or between the two forms of traditional soluble $\mathrm{N}$ fertilizers.

\section{Relative effects of slow release $\mathrm{N}$ - fertilizers.}

Relative effects of slow release $\mathrm{N}$ fertilizers, which calculated as a ratio of the corresponding values of traditional soluble $\mathrm{N}$ - fertilizers, will be used to display the importance of slow release $\mathrm{N}$-fertilizers for the successive crops. Tables ( 3 \& 4) showed means of the relative effects of slow release $\mathrm{N}$-fertilizers for all the experimental factors on dry weigh (gm/pot) and N-uptake (mg/pot) of wheat, sorghum and barley.

The two tabulated data gave similar trends, whereas mean values of relative effects of slow release N-Fertilizers obviously higher in the two successive seasons of summer 2016 sorghum and winter 2016/2017 barley than those in winter season of 2015/2016 wheat for both of dry weights (mg/pots) and $\mathrm{N}$-uptake (mg/pot).

Table (3): Means of relative effects of slow release N-fertilizers on dry weights (gm./pot).

\begin{tabular}{|c|c|c|c|}
\hline \multirow{2}{*}{ Experimental factors } & \multicolumn{3}{|c|}{ Growth Season } \\
\cline { 2 - 4 } & $\begin{array}{c}\text { Winter } \\
2015 / 2016\end{array}$ & $\begin{array}{c}\text { Summer } \\
2016\end{array}$ & Winter 2016/2017 \\
\cline { 2 - 4 } & Wheat & Sorghum & Barley \\
\cline { 2 - 4 } & $\begin{array}{c}\text { Relative effects of slow release N-Fertilizers } \\
\text { (Relative to traditional soluble N-fertilizers, suppose =1) }\end{array}$ \\
\cline { 2 - 5 } & N-Additive & \multicolumn{2}{|c|}{ N-Residues } \\
\hline R1: (2.4 gm.N /pot) & 0.89 & 2.19 & 3.98 \\
\hline R2: (3.6 gm.N /pot) & 0.91 & 2.01 & 4.44 \\
\hline R3: (5.4 gm.N /pot) & 0.96 & 1.91 & 3.31 \\
\hline \multirow{2}{*}{ R -Mean } & 0.92 & 2.04 & 3.91 \\
\hline S1 :(alluvial,"Clay loam") & 0.88 & 1.69 & 3.04 \\
\hline S2 :(Calcar."Sandy clay & 0.95 & 2.19 & 3.72 \\
\hline loam") & 0.95 & 1.94 & 4.36 \\
\hline S3 :(alluvial, "Sandy loam") & 0.92 & 1.94 & 3.71 \\
\hline S-Mean & 0.93 & 2.22 & 3.37 \\
\hline M1: (70\% WHC) & 0.92 & 2.17 & 3.72 \\
\hline M2: (100\% WHC) & 0.92 & 2.20 & 3.55 \\
\hline M -Mean & 0.92 & 2.06 & \\
\hline \hline (Total mean effects) & & & \\
\hline
\end{tabular}


Effect of traditional soluble and slow release $\mathrm{N}$-fertilizers on wheat

Table (4): Means of relative effects of slow release N-fertilizers on N-uptake (mg./pot).

\begin{tabular}{|c|c|c|c|}
\hline \multirow{5}{*}{ Experimental factors } & \multicolumn{3}{|c|}{ Growth Season } \\
\hline & Winter 2015/2016 & $\begin{array}{c}\text { Summer } \\
2016\end{array}$ & Winter 2016/2017 \\
\hline & Wheat & Sorghum & Barley \\
\hline & \multicolumn{3}{|c|}{$\begin{array}{l}\text { Relative effects of slow release N-Fertilizers } \\
\text { (Relative to traditional soluble } \mathrm{N} \text {-fertilizers, suppose =1) }\end{array}$} \\
\hline & $N$-Additive & \multicolumn{2}{|c|}{ N-Residues } \\
\hline R1: (2.4 gm.N /pot) & 0.79 & 2.61 & 4.19 \\
\hline R2: (3.6 gm.N /pot) & 0.82 & 2.42 & 3.62 \\
\hline R3: (5.4 gm.N /pot) & 0.85 & 2.30 & 3.47 \\
\hline R -Mean & 0.82 & 2.44 & 3.76 \\
\hline S1 :(alluvial ,"Clay loam") & 0.78 & 1.96 & 3.22 \\
\hline S2 :(Calcar."Sandy clay loam") & 0.86 & 2.72 & 3.91 \\
\hline S3 :(alluvial, "Sandy loam") & 0.83 & 3.40 & 4.56 \\
\hline S-Mean & 0.82 & 2.69 & 3.90 \\
\hline M1: (70\% WHC) & 0.82 & 2.47 & 3.54 \\
\hline M2: (100\% WHC) & 0.82 & 2.4 & 3.92 \\
\hline M -Mean & 0.82 & 2.44 & 3.73 \\
\hline (Total mean effects) & 0.82 & 2.25 & 3.80 \\
\hline
\end{tabular}

Also, it's important to notice that the relative effects of slow release $\mathrm{N}$ - fertilizers, on dry weights (mg/pots) and N-uptake (mg/pot), were the lowest in the growth season of winter 2015/2016 "wheat", where added $\mathrm{N}$ - fertilizers. While, they increased in the two subsequent growth seasons summer 2016" sorghum" and winter 2016/2017 " barley", whereas no new addition of $\mathrm{N}$-fertilizers, and the growing crops dependent on the residues of the previous addition of $\mathrm{N}$-fertilizers. Also, the highest responded for the residues of slow release $\mathrm{N}$-fertilizers were noticed during the growth season of winter 2016/2017 under growing barley.

The previous trends, as previously explained, can due to slow release $\mathrm{N}$ fertilizers have a continuous supply of crops with their needs of $\mathrm{N}$ for long periods of time. This supply may be continues for many subsequent growth seasons, then for other successive crops as a residual effect (Steve et al., 2012).

\section{Conclusion}

Slow release nitrogen fertilizers can be applied as a pre-plant application, because they may insure adequate supply of $\mathrm{N}$ - 
fertilizers for many successive crops. Thus, reduce production costs and eliminates the need for multiple applications of soluble nitrogen fertilizers. As well as slow release nitrogen fertilizers were able to increase nitrogen use efficiency by reduce nitrogen leachate and volatilization from soils.

\section{REFERENCE}

Allan, H. (2004). Soil properties for plant growth 'A guide to recognizing soil attributes relevant to plant growth and plant selection ' Landcare Research Lincoln Series No. 26, New Zealand.

Aucklah, M., J. Doran, D. Walters, A. Mosler and D. Francis (1991). Crop residue form and placement effects on de-nitrification and mineralization. Soil Science Society of America Journal, 55: 1020-1025.

Black, C. A., D.D. Evans, L. E. Ensminger, J.L. White and F.E. Clark (1965). Methods of Soil Analysis. Agronomy Sevies No. 9, Am. Soc. Agron. Masison, Wisconson, USA.

Dinnes, D. L., D. L. Karlen, D. B. Janes, T. C. Kasper, J. I. Hatfield, T. S. Colvin and C. A. Cambardella (2002). Nitrogen management strategies to reduce nitrate leaching in tile-drained Midwestern soils. Aron, J. 94; 153-171.

Doorenbos, J. and A.H. Kassam (ed) (1986). "Yield Response to Water". FAO Irrigation and Drainage Paper, 33: 164170.

Halvorson, A.D., M.M. Alley and L.S. Murphy (2005). Nutrient requirements and fertilizer use. In. E. G. Heyne (ed.) Wheat and Wheat Improvement. Agronomy 13:345-383.

Irene, S.R., D. B. Dresbøll and K. T. Kristensen (2015). Winter wheat cultivars and nitrogen $(\mathrm{N})$ fertilization-Effects on root growth, $\mathrm{N}$ uptake efficiency and $\mathrm{N}$ use efficiency. Europ. J. Agronomy (68): 38-49.

Khafagi, M., M. Omar and T.A. Aboul Dean (1987). Movement of mineral nitrogen in soils. (1) Movement of nitrate ions. AlAzhar J. Agric. Res. 7: 33-47.
Karrou, M. and J.W. Maranvill (2003). Responses of Wheat Cultivar to Different Soil Nitrogen and Moisture Regimes, Dry Matter Petitioning and Root Growth. Journal of Plant Nutrition, 17 (5): 729744.

Ladha, J.K., H. Pathak, T. Krupnik, J. Six and C. van Kessel (2005). Efficiency of Fertilizer Nitrogen in Cereal Production: Retrospect and Prospects. Advances in Agronomy, 87: 85-156.

Muurnen, S. (2007). Nitrogen dynamics and nitrogen use efficiency of spring cereals under finnish growing conditions. Diss. Uni. Versity of Helsinki, Department of Applied Biology, Publication No:29:38

Ostrom, K. (2011). Comparing the effect of controlled release, slow- release and water soluble fertilizers on plant growth and nutrient leaching. MSc. Thesis, The Ohio State University.

Piper, C. S. (1950). Soil and Plant Analysis. Inter-science Pub. nc. 25:50-54.

Poutala, T. (1998). Improving resource efficiency in nutrient management of cereal cropping systems. University of Helsinki, Department of Plant Production, Section Crop Husbandry, Publication no,54, $109 \mathrm{p}$.

Przulj, N. and V. Momcilovic (2001). Genetic variation for dry matter and nitrogen accumulation and translocation in tworowed spring barley II. Nitrogen translocation. European Journal of Agronomy, 5: 255-265.

Rajala, A. and P. Peltonen-Sainio (2013). Slow-release fertilizer to increase grain $\mathrm{N}$ content in spring wheat. Agricultural and Food Science, 22: 318-324.

Shaviv, A. (2001). Improvement of fertilizer efficiency- Product Processing, Positioning and Application Methods. Proceedings 469, International Fertilizer Society, York, UK. Pp 23.

Shaviv, A. (2005). Controlled Release Fertilizers. IFA International Workshop on ENHanced-Efficiency Fertilizer, Frankfurt. International Fertilizer Industry Association Paris, France. 
Silva, G. H., Kaufman, K. Walton, T. Gruesbeck and G. Parr (2007). Comparing slow release nitrogen with traditional nitrogen and moisture sources on corn yield.Michigan State University Extension. www.msue.msu.edu.

Slack, J. K. and R. Hatch (1967). The effect of soil management on available nitrogen. Stikstof, N. 12, 132-143

Snedecor, G.W. and W.G. Coehran (1971). Statistical Methods. 7 th ed lowa Stte Univ. Press, Ames

Steve, O., W. Steve and M. Ottman (2012). Nirrogen management impacts on wheat yield and protein. Proceedings, California Alfalfa \& Grains Symposium,

Sacramento, CA, December 11-12. UC. Trenkel, M. E. (Ed) (2010). Slow-and Controlled-Release and Stabilized Fertilizers: An Option for ENHancing Nutrient Use Efficiency in Agriculture. International fertilizer industry Association (IFA) Paris, France. (1-160 pp.)

Ustimenko-Bakumovsky, G. V. (ed.) (1983). Plant Growing in the Tropics and Subtropics. Translated from Russian, First Published 1983. p.96-113.

\section{تأثير استخدام الأسمده النتروجينية بطيئة وسريعة الذوبان على محصول القمح مع دراسة لتأثير ها المتبقى على ذرة العلف و الثُعير}

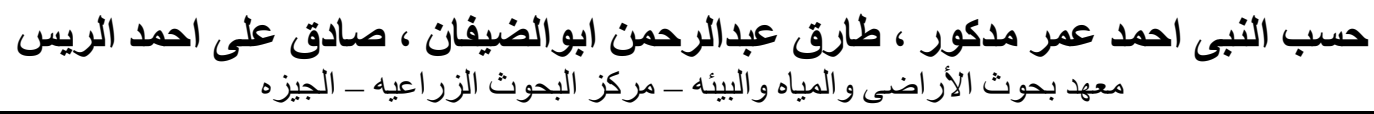

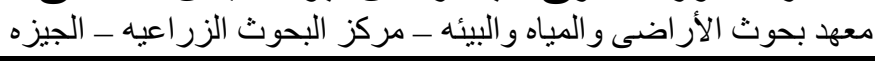

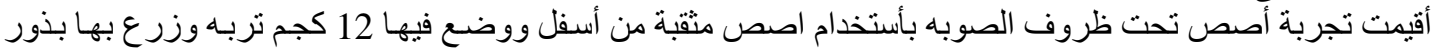

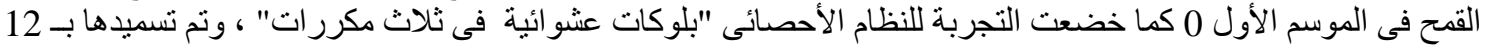

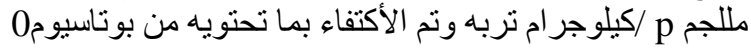




\section{H. A. Madkour, et al.,}

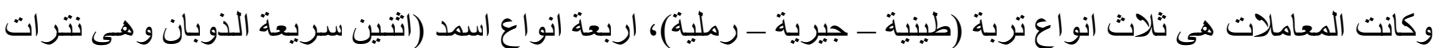

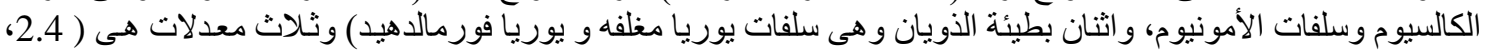

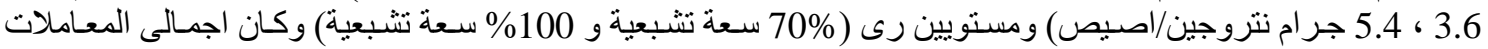

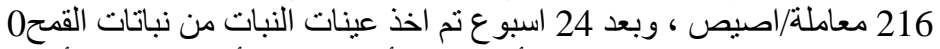

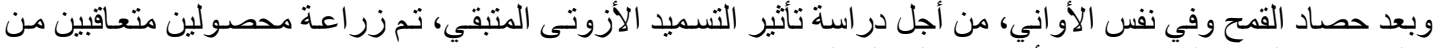

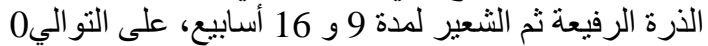

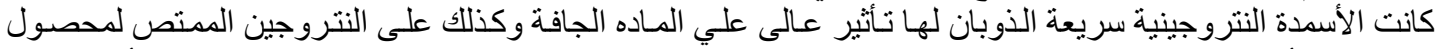

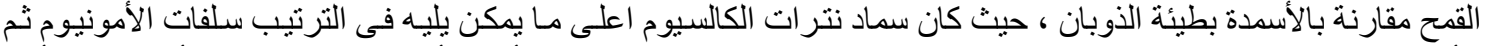

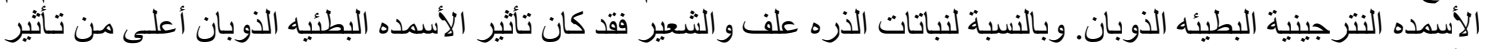

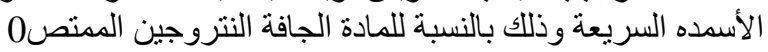

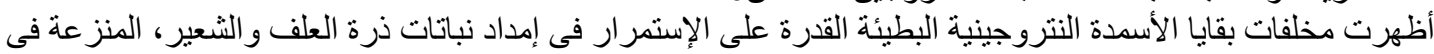

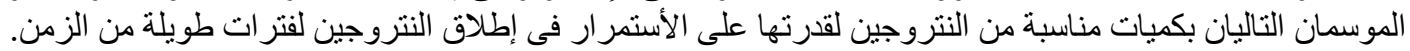

